\title{
El desminado en Colombia: mecanismo de disuasión utilizado en la negociación del conflicto armado, para el logro de una paz estable y duradera
}

Cristhian Fernando Sánchez Giraldo*

\section{Introducción}

Todas las guerras significan el fracaso de los mecanismos de resolución de conflictos, y todas ellas necesitan de la reconstrucción de la fe y la confianza en la posguerra.

(Abdul Kalam)

El fin de la Guerra Fría significo para el mundo la terminación de la bipolaridad económica, política, cultural y armamentista, siendo este último aspecto el más importante para la consecución de la paz y estabilidad mundial, pues la constante tensión nuclear a la que se veía avocada la comunidad internacional había terminado, o eso era lo que se suponía. Sin embargo, esta no fue la única amenaza latente que existía, ya que las secuelas de las guerras pasadas dejaron otros tipos de armas mucho más mortales y letales, que permanecerían como enemigos invisibles, silenciosos, hasta que alguien las encontrara en su camino y le recordara al mundo que nunca hubo fin.

\footnotetext{
Profesional en Relaciones Internacionales de la Universidad Jorge Tadeo Lozano; magíster en Relaciones Internacionales de la Pontificia Universidad Javeriana y candidato a Ph.D. en Ciencia Política de la Universidad Complutense de Madrid. Profesor titular de la Facultad de Gobierno y Relaciones Internacionales de la Universidad Santo Tomás. Correo electrónico: cristhiansanchez@usantotomas.edu.co
} 
Son estas, las minas antipersonales (MAP), armas de efecto retardado que han producido más víctimas que las nucleares y químicas, simultáneamente.

La introducción de las MAP en los conflictos armados tiene sus orígenes en la Primera Guerra Mundial, cuando el ejército alemán emplazaba casquetes de artillería rellenos de pólvora o dinamita con un detonador a ras de tierra, con el fin de evitar el avance de los tanques franceses y británicos (Unicef, 2000). También fueron utilizadas durante la Segunda Guerra Mundial, en Europa y el norte de África. Asimismo, el Comité Internacional de la Cruz Roja manifestó que en Libia y Egipto se utilizaron para paliar la falta de obstáculos naturales en los desiertos, y en la guerra de Vietnam las minas eran dispersadas manualmente o por vía aérea para apoyar a las tropas en tierra (Roa, 2000).

En Colombia las MAP aparecen a partir de 1970. El Ejército Nacional las utilizaba para proteger los batallones y centros de operaciones logísticas, las Fuerzas Armadas Revolucionarias de Colombia (FARC), el Ejército de Liberación Nacional (ELN) y posteriormente los paramilitares las comenzaron a usar para cuidar cultivos ilícitos y defenderse del enemigo. Se constituyeron en armas letales, silenciosas y efectivas. Sin embargo, tras su uso indiscriminado y prohibida su práctica internacional, el Ejército Nacional decidió quitar las que tenía emplazadas y abolir definitivamente su uso. Desafortunadamente, los grupos al margen de la ley siguen usándolas y perfeccionando su fabricación, a tal punto que son cada vez más mortales y difíciles de encontrar.

Cincuenta años de conflicto armado dejan alrededor de 220.000 muertos, 6.000.000 de desplazados y cerca de 11.481 víctimas causadas por la utilización de MAP, entre los que se encuentran civiles, fuerza pública, combatientes y no combatientes (Programa Presidencial para la Acción Integral Contra Minas Antipersonal [PAICMA], 2017); su uso es una clara violación a los derechos humanos y una contravención al derecho internacional humanitario. De los 1123 municipios que tiene el país, 688 poseen minas emplazadas en sus territorio (Dirección para la Acción Integral Contra Minas Antipersonal [DAICMA], 2016).

En la actualidad no hay información que permita establecer con certeza cuántos campos minados existen, en qué zonas se encuentran concretamente ubicados y mucho menos cuántos artefactos explosivos hay emplazados ${ }^{11}$ hoy en el país. La falta de

\footnotetext{
$1 \quad$ Se utiliza el término de emplazar teniendo en cuenta la sugerencia de la profesora Andrea Ortega Torres de la Universidad Sergio Arboleda (Ortega Torres, 2016), que hace una apreciación sobre la importancia de utilizar esta palabra, resaltando que la Real Academia Española la define como: poner una cosa en determinada zona, en lugar de siembra, puesto que para los efectos de articular esta palabra con algo tan inhumano como lo son los artefactos explosivos, necesariamente sería contradecir el concepto positivo del término. Para los habitantes de las zonas rurales en Colombia, la acción de sembrar está directamente relacionada con plantar una semilla en la tierra, esperando que esta de frutos y así lograr la productividad de la tierra.
} 
una carta de navegación geográfica clara y el falso desconocimiento por parte de las FARC $^{2}$ sobre su posible ubicación han hecho que esta situación empeore con el paso del tiempo, y han puesto en riesgo la vida de miles de personas inocentes, aun después de terminado el conflicto armado.

Figura 1. Cartografía de las víctimas de minas antipersonal en Colombia

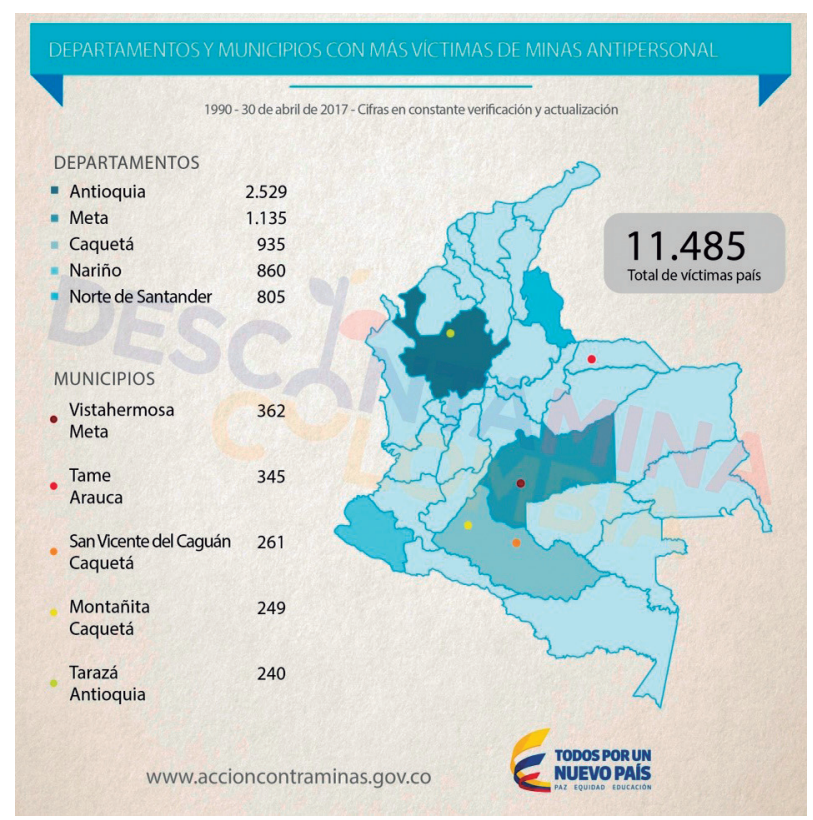

Fuente: PAICMA (2017).

El Gobierno colombiano hace más de 20 años ha intentado frustradamente consolidar una política seria de desminado en el país, que contribuya no solo al logro de la paz, sino también a la restitución de los derechos humanos que han sido vulnerados a miles de personas a lo largo del conflicto armado, más aún cuando Colombia hace parte de la convención de Ottawa, ${ }^{3}$ que lo obliga internacionalmente a desminar

2 Las FARC fue el principal grupo guerrillero de Colombia, cuenta con unos 9200 combatientes y 48 años de lucha armada.

3 Colombia firmó la convención sobre la prohibición del empleo, almacenamiento, producción y transferencia de minas antipersonal y sobre su destrucción (Tratado de Ottawa) el 3 de diciembre de 1997. Ratificó el 6 de septiembre de 2000 y entró en vigor el 1 de marzo de 2001. 
totalmente el territorio para $2021^{4}$. El acuerdo de paz firmado entre el Gobierno y las FARC permite nuevamente abordar el inhumano tema del desminado desde la perspectiva del gana/gana, que no solo favorece los intereses políticos de este grupo, sino que además contribuye al logro mediático de la paz en términos de costo/beneficio, ya que el ámbito de la negociación permite utilizar todos los mecanismos y medios legales para que cada una de las partes logre superar los objetivos propuestos.

El proceso de desminado en Colombia tiene como finalidad liberar aquellos territorios contaminados con MAP y artefactos explosivos emplazados por la guerrilla de las FARC tras el conflicto armado, para ser nuevamente utilizados y habitados libremente por las víctimas del conflicto. Dicho proceso, considerado para muchos expertos el talón de Aquiles del acuerdo de paz, se ha convertido en un tema difícil, complejo y riesgoso para su cumplimiento en el corto plazo. A enero de 2017, se habían priorizado 207 municipios, 22 de los cuales están en operaciones de desminado.

Sin embargo, dada la gran extensión de terreno afectado por estos artefactos, la dificultad radica, teniendo en cuenta la duración e intensidad del conflicto, en conocer con certeza dónde están actualmente ubicados, cómo fueron colocadas y su erradicación definitiva; de esa manera se podrá garantizar a las víctimas que las tierras vuelvan a ser fértiles para el agro y la ganadería, y obviamente para su retorno. Cabe mencionar, a modo de contextualización, que en San Carlos (Antioquia), el primer municipio del país declarado libre de minas, los campesinos encontraron cuatro artefactos en las veredas Santa Rita y La Mirandita, tras ser declaradas "limpias" (RCN Radio, 2016).

En Colombia, las FARC y el Gobierno han utilizado el tema del desminado frente a las negociaciones de paz como un mecanismo de disuasión y presión para el logro de sus fines políticos. Primero, porque sin la erradicación de los artefactos explosivos no se podrá construir una verdadera paz estable y duradera, ${ }^{5}$ no se podrán restituir territorios ni habrá retorno de victimas a los estos, y como consecuencia la violencia podría incrementarse en las zonas de conflicto; segundo, porque para este grupo es de vital importancia garantizar su inserción en la vida civil y política por medio de acciones que contribuyan a la reparación de los daños humanos y materiales causados a las víctimas.

4 La Convención de Ottawa reitera que será obligación de los Estados parte llevar a cabo sus mayores esfuerzos, para "identificar todas las zonas bajo su jurisdicción o control donde se sepa o se sospeche que hay minas antipersonal, y adoptará todas las medidas necesarias, tan pronto como sea posible, para que todas las minas antipersonal en zonas minadas bajo su jurisdicción o control tengan el perímetro marcado, estén vigiladas y protegidas por cercas u otros medios para asegurar la eficaz exclusión de civiles, hasta que todas las minas antipersonal contenidas en dichas zonas hayan sido destruidas".

5 Terminología empleada para denominar el Acuerdo de paz en Colombia, cuyo nombre completo es: Acuerdo de paz final para la terminación del conflicto y la construcción de una paz estable y duradera. 


\section{Breve descripción del proceso de desminado humanitario en Colombia}

El desminado humanitario es una política prioritaria del Gobierno colombiano, asumida por la Alta Consejería para el Posconflicto, Derechos Humanos y Seguridad. En teoría, se refiere a la asistencia humanitaria proporcionada a las poblaciones afectadas por los "eventos" 6 ocasionados por el emplazamiento de minas antipersonal (MAP) y de municiones sin explosionar (MUSE). Tiene como objetivo librar a todos los territorios contaminados por estos artefactos para permitirle a la población la libre circulación que se mantenía restringida por la constante amenaza de las minas y para poder ser habitados nuevamente por las víctimas del conflicto armado (DAICMA, 2014).

Transversalmente, el desminado humanitario permite el desarrollo de políticas públicas encaminadas a garantizar la restitución, propiedad y titulación de tierras; el retorno de las comunidades desplazadas a sus lugares de origen, la recuperación de terrenos violentados por cultivos ilícitos y la ejecución de otras políticas dirigidas al desarrollo rural de las poblaciones afectadas, para proporcionarles así el goce pleno de sus derechos fundamentales vulnerados a lo largo del conflicto.

El desminado desde esta perspectiva se convierte, entonces, en una actividad trascendental para el cumplimiento del acuerdo de paz en el posconflicto y la consecución de esta a mediano plazo, más aun cuando las partes involucradas (Fuerzas Militares, FARC, Gobierno) logran por primera vez realizar el proceso de desminado en un escenario sin guerra, en zonas geográficas vetadas e inhóspitas a las cuales no se podía fácilmente acceder.

El uso doloso de MAP y de artefactos explosivos tiene repercusiones aterradoras e irreparables para la sociedad. Sus consecuencias trascienden más allá de la terminación del conflicto, se prolongan en el tiempo, durante décadas, generación tras generación. El emplazamiento de las MAP en un territorio determinado no significa meramente un problema mediático o coyuntural para un país en conflicto, sino que representa a todas luces un inconveniente a largo plazo para el logro verdadero de la paz y, claramente, un obstáculo para el desarrollo sistémico de la sociedad en el posconflicto.

Como parte complementaria del acuerdo de paz firmado actualmente con las farc, el Gobierno de Colombia dio inicio al Plan Estratégico de Desminado

6 Teniendo en cuenta el Glosario Nacional Básico General de Términos de Acción Integral contra Minas Antipersonal, al emplear la palabra "eventos" se hace referencia a la definición que corresponde tanto a los accidentes, como a los incidentes causados por las MAP, los artefactos explosivos improvisados (AEI) y MUSE o restos explosivos de guerra (REG) en general. En el caso de los accidentes, el mismo glosario señala que son acontecimientos indeseados causados por MAP, MUSE o AEI que causan daño físico y psicológico a una o más personas, y para el caso de los incidentes debe entenderse que es todo acontecimiento relacionado con MAP, MUSE O AEI que puede aumentar hasta un accidente o que tiene el potencial para conducir a un accidente (DAICMA, 2014). 
Humanitario, el cual debe ser ejecutado hasta el 2021. Este consiste en descontaminar 673 municipios ( $60 \%$ del país) de 28 departamentos ${ }^{7}$ del territorio nacional donde se sospecha que hay MAP. Esta labor cuenta con la asistencia conjunta de las fuerzas militares, organizaciones no gubernamentales (ONG) líderes en el tema ${ }^{8}$ y el grupo de excombatientes pertenecientes a las FARC.

El plan mencionado está soportado con la aplicación de tecnología de punta para desminado, como máquinas desminadoras, uso de caninos y técnica manual, utilizada en países como Afganistán, Ucrania, Angola e Irak, entre otros. ${ }^{9}$

El desarrollo de estas actividades, según el DAICMA, tendrá un costo aproximado de 327.97 millones de dólares, ${ }^{10}$ ya que desminar cada metro cuadrado puede costar alrededor de 6 dólares y nuestro país tiene más de 52 millones de metros cuadrados emplazados con MAP y artefactos explosivos (un área equivalente a casi la extensión territorial del distrito metropolitano de Manhattan, Nueva York) se supone que más del $50 \%$ de estos terrenos podrían ser productivos y, adicionalmente, tienen en curso procesos de restitución de tierras y sustitución de cultivos ilícitos.

Los departamentos que han registrado el mayor número de víctimas por esta causa son Antioquia (2524), Meta (1134), Caquetá (933), Nariño (858) y Norte de Santander (803), y un total nacional de 11.460 víctimas reportadas en los últimos 26 años (registro realizado a partir de 1991), de las cuales el 38,7\% son civiles (DAICMA, 2017).

7 Según el DAICMA, diez regiones concentran el mayor número de minas emplazadas: el suroriente colombiano, el Catatumbo, las selvas del Sarare, el Suroriente antioqueño, el Nudo de Paramillo, el Sur de Bolívar, los Montes de María, el Cañón de las Hermosas, la frontera con el Ecuador a la altura de Putumayo y la Sierra Nevada de Santa Marta.

8 Hazardous Areas Life-Support Organization (HALO) Trust es una organización no gubernamental de carácter humanitario y beneficencia, sin fines políticos, religiosos o económicos, que se especializa en la eliminación de MAP y MUSE, mediante el desminado humanitario. Desde 2009, HALO instaló sus oficinas en Colombia y a partir de septiembre de 2013 inició operaciones de desminado, con el compromiso de "sacar las minas de la tierra, para siempre", siendo la primera organización en el país acreditada para operar con civiles.

9 Previo a la aplicación de las técnicas para el desminado humanitario, se deben llevar a cabo tres importantes actividades, a saber: 1) estudio no técnico: implica la recolección y el análisis de información con todas las fuentes disponibles susceptibles de poseer datos sobre contaminación de MAP y MUSE, así como investigación en el terreno desde un área considerada segura, para recolectar nuevas evidencias que confirmen o desvirtúen la sospecha que tuvo la comunidad; 2) estudio técnico: es una investigación en profundidad mediante intervención física invasiva, para confirmar o cancelar áreas peligrosas con posible presencia de MAP y MUSE. Si se confirma, se delimita el área peligrosa que posteriormente será intervenida con despeje. De lo contrario, se cancela; 3 ) despeje: tareas o acciones para remover o destruir todos los peligros de minas y restos explosivos de guerra (REG) en un área peligrosa confirmada a una profundidad específica (DAICMA, 2017).

10 El costo del plan estratégico está distribuido en seis líneas de intervención: 1) coordinación nacióndepartamento-municipio USD 7,30 millones (2\%); 2) educación en el riesgo usD 3,18 millones (1\%); 3) asistencia a víctimas usD 7,48 millones (2\%); 4) desminado humanitario usD 301,97 millones (92\%); 5) gestión de información USD 6,29 millones (2\%), y 6) evaluación de impacto USD 1,75 millones (1\%). 
Figura 2. Cartografía de posible desminado en territorios con minas antipersonal emplazadas por las FARC

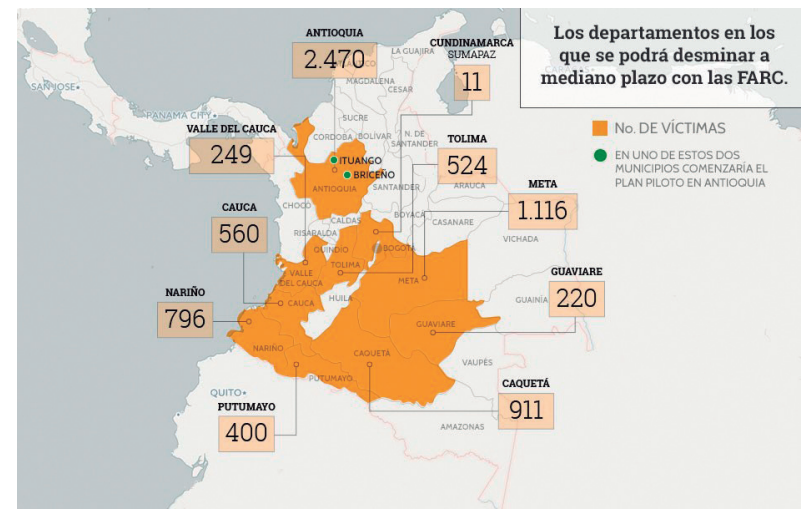

Fuente: El Tiempo. http://www.eltiempo.com/multimedia/especiales/situacion-de-minas-antipersonaen-colombia/15714557/1/index.html

Figura 3. Operaciones de liberación de tierras con minas antipersonal en Colombia

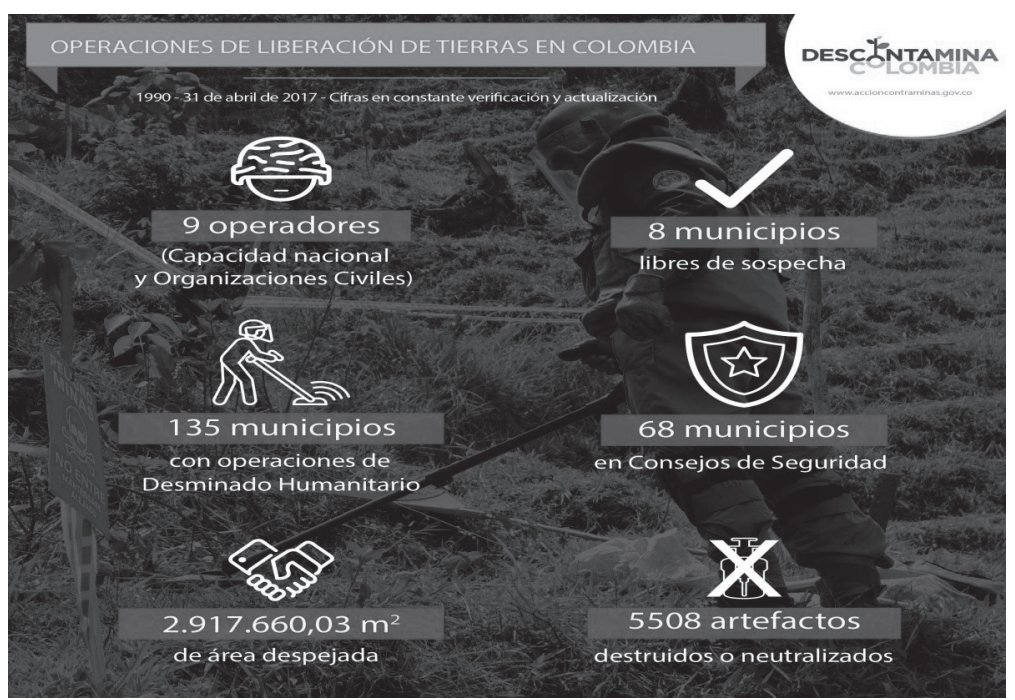

Fuente: PAICMA (2017). 
La figura 3 nos muestra las operaciones de liberación de tierras que se llevan a cabo en el país, a través del Plan Estratégico para el Desminado, el cual tiene preestablecidas unas líneas de intervención que suponen:

- Desminado humanitario. Proceso de aplicación de todo esfuerzo razonable para identificar, definir y remover toda contaminación o sospecha de MAP y MUSE en un territorio.

- Coordinación nación-territorio. Conjunto de acciones de articulación, interlocución, coordinación y seguimiento con las entidades territoriales y demás actores involucrados, para la implementación de la Acción integral contra Minas Antipersonal (AICMA) en el territorio.

- Educación en el riesgo por minas. Conjunto de procesos dirigidos a la población civil, que busca sensibilizar y fomentar una cultura de comportamientos seguros ante el riesgo por la presencia de minas antipersonal y municiones sin explosionar. La estrategia implica una gran campaña de señalización de las áreas con sospecha de contaminación por minas o municiones sin explotar.

- Asistencia integral a víctimas. Impulsar el acceso de las víctimas de MAP y MUSE a la ruta de atención, asistencia y reparación integral en articulación con las entidades responsables.

- Gestión de Información. Recolección, almacenamiento, análisis, validación y diseminación de la información relativa a la AICMA. Será necesario microfocalizar el territorio a nivel vereda, para conocer el tamaño real de la contaminación.

- Evaluación de Impacto. Análisis del impacto de las minas sobre la población y el territorio afectado antes y después de la intervención de AICMA. Implica identificación de los derechos vulnerados y el impacto sobre su restitución. 
Figura 4. Técnicas utilizadas para el proceso de desminado humanitario

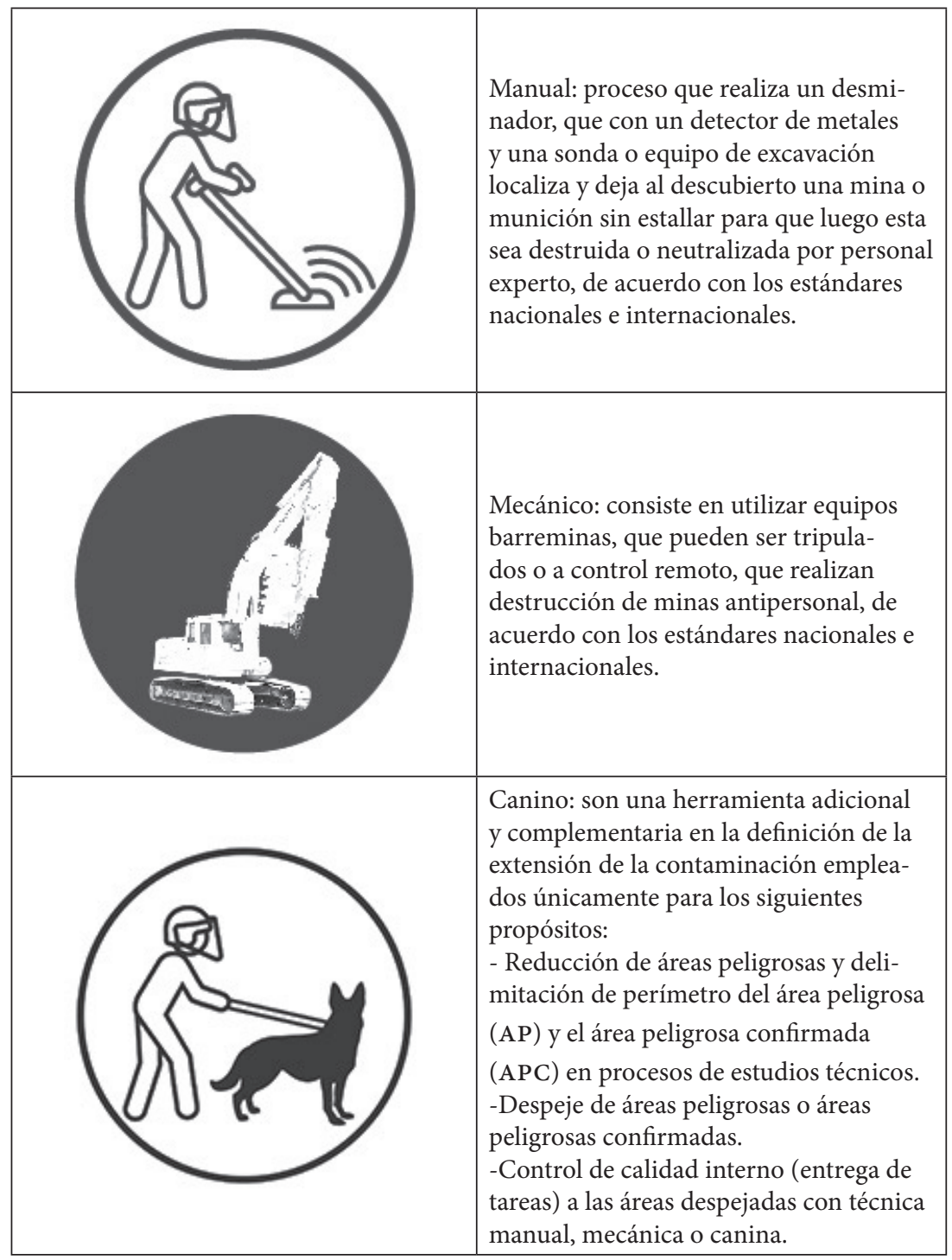

Fuente: PAICMA (2017).

Para la aplicación de las técnicas de desminado, es necesario identificar inicialmente cuatro tipologías de afectación (alta, media, baja y sin afectación), con base en las cuales se determinará la prioridad de intervención en los próximos cinco años. 
Tabla 1. Tipos de municipios y costos del desminado

\begin{tabular}{|c|c|}
\hline \multirow{5}{*}{$\begin{array}{c}\text { Tipo I: } \\
199 \text { municipios con } \\
\text { alta afectación } \\
\text { Costo desminado } \\
\text { US } \$ 293,5 \text { millones }\end{array}$} & $\begin{array}{l}\text { Estos municipios están ubicados en } 28 \text { departamentos. Este grupo } \\
\text { corresponde al } 17,74 \% \text { del total de municipios del país. }\end{array}$ \\
\hline & $\begin{array}{c}\text { En los municipios de esta tipología se concentra el 75,6\% de los accidentes } \\
\text { ocurridos en Colombia entre } 1990 \text { y diciembre de } 2015 \text {, así como el } \\
71,54 \% \text { de las víctimas de la población civil y el } 76,19 \% \text { de las víctimas } \\
\text { miembros de la fuerza pública, reportadas en el mismo periodo. }\end{array}$ \\
\hline & $\begin{array}{l}\text { En cuanto a las solicitudes de restitución de tierras, el } 56,49 \% \text { de los } \\
\text { predios solicitados están ubicados en municipios que pertenecen a esta } \\
\text { tipología. }\end{array}$ \\
\hline & $\begin{array}{l}\text { El 91,19\% de hectáreas con cultivos de coca registradas en el país se } \\
\text { encuentra en municipios clasificados en esta tipología. }\end{array}$ \\
\hline & En estos municipios hay presencia de guerrilla de las FARC y del ELN. \\
\hline \multirow{4}{*}{$\begin{array}{c}\text { Tipo II: } \\
291 \text { municipios con } \\
\text { media afectación } \\
\text { Costo desminado } \\
\text { US\$34 millones }\end{array}$} & $\begin{array}{l}\text { Estos municipios están ubicados en } 28 \text { departamentos del país. Este grupo } \\
\text { corresponde al } 25.94 \% \text { del total de municipios del país. }\end{array}$ \\
\hline & $\begin{array}{l}\text { En los municipios de esta tipología se concentra el 14,95\% de los } \\
\text { accidentes ocurridos en Colombia entre } 1990 \text { y diciembre de } 2015 \text { (de los } \\
\text { registros históricos), así como el 18,69\% de las víctimas de la población } \\
\text { civil y el 15,68\% de las víctimas miembros de la fuerza pública, reportadas } \\
\text { en el mismo periodo. }\end{array}$ \\
\hline & $\begin{array}{l}\text { En cuanto a las solicitudes de restitución de tierras, el } 24,35 \% \text { de los } \\
\text { predios solicitados están ubicados en municipios que pertenecen a esta } \\
\text { tipología. }\end{array}$ \\
\hline & $\begin{array}{c}\text { El 3,17\% de hectáreas con cultivos de coca registradas en el país estáen } \\
\text { municipios clasificados en esta tipología. }\end{array}$ \\
\hline
\end{tabular}




\begin{tabular}{|c|c|}
\hline $\begin{array}{l}\text { Tipo III: } \\
183 \text { municipios con } \\
\text { baja afectación } \\
\text { Costo desminado }\end{array}$ & $\begin{array}{l}\text { Los municipios clasificados en esta tipología no cuentan con reportes } \\
\text { de accidentes con MAP y MUSE en el IMSMA.111 No obstante, en estos } \\
\text { municipios se ha presentado un bajo número de acontecimientos } \\
\text { relacionados con MAP y MUSE sin víctimas (incidentes) tales como } \\
\text { desminado militar en operaciones e incautaciones de MAP o MUSE. Estos } \\
\text { municipios se encuentran ubicados en } 27 \text { departamentos del país. Este } \\
\text { grupo corresponde al 16,31\% del total de municipios del país. }\end{array}$ \\
\hline & $\begin{array}{l}\text { En cuanto a las solicitudes de restitución de tierras, el 4,86\% de los predios } \\
\text { solicitados están ubicados en municipios que pertenecen a esta tipología. }\end{array}$ \\
\hline $\begin{array}{c}\text { Tipo IV: } \\
429 \text { municipios sin } \\
\text { afectación registrada } \\
\text { Costo desminado } \\
\text { US\$72.757 millones }\end{array}$ & $\begin{array}{l}\text { Se compone por } 429 \text { municipios que no presentan registro de eventos } \\
\text { por MAP y MUSE en el IMSMA. Estos se encuentran ubicados en } 28 \\
\text { departamentos. Este grupo corresponde al 38,24\% del total de municipios } \\
\text { del país. }\end{array}$ \\
\hline
\end{tabular}

Fuente: elaboración propia, a partir de datos del DAICMA (2017).

\section{Marco normativo del desminado humanitario en Colombia ${ }^{11}$}

Según la Ley 554 de 2000, el Estado colombiano es parte de la Convención sobre la Prohibición del Empleo, Almacenamiento, Producción y Transferencia de Minas Antipersonal y sobre su destrucción, denominada Convención de Ottawa. En sus artículos 4 y 5, dicha convención ordena al Estado colombiano adoptar las medidas necesarias para que todas las minas antipersonal en zonas bajo su jurisdicción tengan el perímetro marcado y estén vigiladas y protegidas por cercas u otros medios, con el fin de asegurar la exclusión de civiles hasta que estas sean destruidas.

A través de la Ley 759 de 2002 se establece un régimen penal para castigar el empleo, la producción, comercialización y el almacenamiento de minas antipersonal, y se crea la Comisión Intersectorial Nacional para la Acción contra Minas Antipersonal (CinAmap), en cabeza del vicepresidente de la República, como autoridad nacional en los temas relativos a las minas antipersonal y las municiones sin explotar.

11 DAICMA (2017). 
Mediante el Decreto 2150 de 2007 se creó el PAICMA, para ejercer las funciones de secretaría técnica de la autoridad nacional (CINAMAP) en los temas relativos a las minas antipersonal y las municiones sin explotar, bajo la coordinación de la Vicepresidencia de la República.

La Ley 1421 de 2010, en su artículo 9, otorga facultades al Gobierno nacional, a través del Ministerio de Defensa Nacional, para adoptar las medidas necesarias sobre la base de los estándares internacionales y los principios humanitarios. Esto para reglamentar las actividades de desminado humanitario, de forma que pueda ser realizado por organizaciones civiles, con el propósito de garantizar el goce efectivo de los derechos y libertades fundamentales de las comunidades afectadas por la violencia armada en Colombia.

El Decreto 3750 de 2011, que reglamenta el artículo 9 de la Ley 1421 de 2010, establece la Instancia Interinstitucional de Desminado Humanitario como el ente interinstitucional adscrito al Ministerio de Defensa Nacional, encargado de implementar y dirigir la ejecución de actividades de Desminado Humanitario realizadas por organizaciones civiles de desminado humanitario.

Tabla 2. Evolución de las minas antipersonales en Colombia

\begin{tabular}{|l|l|}
\hline \multicolumn{1}{|c|}{ Años } & \multicolumn{1}{c|}{ Acontecimiento } \\
\hline $1914 / 1918$ & $\begin{array}{l}\text { La Primera Guerra Mundial se libró en trincheras, donde se introdujo el uso sistemá- } \\
\text { tico de MAP. }\end{array}$ \\
\hline $1938 / 1945$ & $\begin{array}{l}\text { El modelo de producción en masa contribuyó a que, durante la Segunda Guerra } \\
\text { Mundial, la industria militar desarrollara un mayor número de minas antipersonal. }\end{array}$ \\
\hline 1970 & $\begin{array}{l}\text { A partir de esta década se empezaron a usar las minas antipersonal en Colombia, como } \\
\text { arma de guerra. El Ejército Nacional producía minas tipo MAP1 y MAP2, para proteger } \\
\text { sus batallones. Las FARC y el elN, por su parte, las comenzaron a utilizar para proteger } \\
\text { los cultivos ilícitos y para detener al enemigo. }\end{array}$ \\
\hline 1977 & $\begin{array}{l}\text { Se firma la Convención de Ginebra, donde se prohíbe usar armas indiscriminadas } \\
\text { contra la población civil en tiempos de guerra. }\end{array}$ \\
\hline 1980 & $\begin{array}{l}\text { La ONU celebra el Convenio sobre Ciertas Armas Convencionales, que prohíbe usar } \\
\text { armas consideradas excesivamente nocivas o de efectos indiscriminados. }\end{array}$ \\
\hline 1981 & $\begin{array}{l}\text { Ocurrencia del primer evento ocasionado por la explosión de minas antipersonal en } \\
\text { Colombia. Este se produjo en Corinto, Cauca, el 22 de enero de este mismo año. }\end{array}$ \\
\hline 1990 & $\begin{array}{l}\text { Se empieza a realizar el registro y conteo oficial de víctimas por minas antipersonal en } \\
\text { Colombia. }\end{array}$ \\
\hline 1993 & $\begin{array}{l}\text { Las FARC oficializan el uso de minas antipersonal, como parte de su estrategia de } \\
\text { guerra. }\end{array}$ \\
\hline 1996 & $\begin{array}{l}\text { El Ministerio de Defensa prohíbe a la Industria Militar Colombiana (Indumil) la pro- } \\
\text { ducción de MaP en Colombia. }\end{array}$ \\
\hline
\end{tabular}




\begin{tabular}{|c|c|}
\hline 1997 & $\begin{array}{l}\text { Firma de la Convención de Ottawa, la cual prohíbe la utilización, almacenamiento y } \\
\text { fabricación de MAP. }\end{array}$ \\
\hline 1999 & Entra en vigor la Convención de Ottawa, ratificada por 123 Estados. \\
\hline 2000 & El Congreso de Colombia ratifica la Convención de Ottawa. \\
\hline 2001 & $\begin{array}{l}\text { Colombia se compromete internacionalmente a desminar el territorio nacional en un } \\
\text { periodo de diez años. }\end{array}$ \\
\hline 2005 & El Ministerio de Defensa crea el Batallón de Desminado. \\
\hline 2011 & $\begin{array}{l}\text { Colombia no logra desminar su territorio tras diez años de la entrada en vigor de la } \\
\text { Convención de Ottawa y pide prórroga internacional por diez años más. }\end{array}$ \\
\hline 2012 & La Vicepresidencia de la República crea el Observatorio de Minas Antipersonal. \\
\hline 2014 & $\begin{array}{l}\text { En el marco de las negociaciones de paz en La Habana, Cuba, el Gobierno y las FARC } \\
\text { llegan a un acuerdo sobre desminado y erradicación de cultivos ilícitos. }\end{array}$ \\
\hline 2015 & Se da inicio al Plan Piloto de Desminado Humanitario. \\
\hline 2016 & $\begin{array}{l}\text { Se firma el acuerdo de paz entre el gobierno y las FARC, y se determinan las condi- } \\
\text { ciones para continuar con el proceso de desminado y así cumplir con la obligación } \\
\text { internacional de librar a Colombia de MAP en } 2021 \text {. }\end{array}$ \\
\hline
\end{tabular}

\section{Retos y desafíos del desminado en Colombia}

Sin lugar a dudas alcanzar la paz tiene un precio y Colombia ha pagado uno muy alto por conseguirla, no solo por los daños económicos que el país ha tenido que asumir, sino también por todas las victimas que el conflicto ha dejado tras su paso, las que sobrevivieron para contar su tragedia tendrán que ser reparadas irremediablemente para que la paz verdadera trascienda y su goce sea visible por todo el pueblo colombiano y la comunidad internacional.

En ese orden de ideas, el desminado como argumento necesario para la implementación de los acuerdos de paz y su garantía se convierte en el eje principal del posconflicto, lo que fortalece la efectividad de otros procesos como la restitución de tierras, el retorno de desplazados a sus lugares de origen y la sustitución de cultivos ilícitos. Estos son retos urgentes que debe superar el gobierno nacional si se quiere cumplir a cabalidad con el compromiso de ser un país libre de sospecha de minas en 2021.

Sin embargo y teniendo en cuenta la compleja labor que se requiere para desminar las zonas afectadas por el emplazamiento de MAP, ¿por qué el Gobierno colombiano se comprometió internacionalmente y en tan corto tiempo (2016-2021) a descontaminar el territorio de las MAP y artefactos explosivos, aun sabiendo por experiencias dadas en otros países con conflictos similares que el desminado es una actividad 
que puede perdurar décadas para su erradicación total ${ }^{12}$ ¿Es acaso un mecanismo de disuasión que permitirá conseguir la aprobación e implementación definitiva del acuerdo de paz?

"El fin justifica los medios”..., decía Maquiavelo en su obra política El Príncipe y nada más acorde y aplicable a la coyuntura actual del país tras la consolidación del nuevo escenario de paz. En el caso del desminado, el fin que es la paz justifica que el Gobierno se comprometiera a realizar un proceso que desde su inicio es imposible de cumplir. En las negociaciones llevadas a cabo en La Habana se discutieron temas relevantes para el desarrollo y futuro del país, los cuales quedaron materializados en un acuerdo encaminado a la consecución de la paz, verdad, perdón, justicia y reparación de las víctimas, y se determinó la forma como se incorporarían a la legalidad y democracia aquellos que infringieron la ley por tantos años al cometer todo tipo de crímenes, siendo los de mayor impacto los de lesa humanidad ${ }^{13}$.

Pero el acuerdo por sí solo no representa la solución a los problemas estructurales del país, ni a la terminación de la guerra, pues deberá no solo cumplirse a cabalidad cada uno de sus puntos, sino que también tendrán que superarse diversos factores políticos, económicos y sociales que inciden en su aplicabilidad.

Existen varios motivos con los cuales se podría argumentar por qué Colombia no alcanzará en el mediano plazo cumplir a cabalidad el compromiso que adquirió internacionalmente con la firma de la Convención de Ottawa, de desminar en 2021 todo el territorio nacional. A continuación, algunas justificaciones al respecto:

- No existe georreferenciación ni mapeo alguno que permita identificar con seguridad las zonas donde se encuentran actualmente emplazadas las MAP. Esta situación genera un aumento injustificado de tiempo y mano de obra a lo estimado inicialmente por el Gobierno y las organizaciones involucradas, lo que eleva considerablemente los costos del presupuesto destinado para dicha operación.

12 Hasta el momento ocho municipios han sido declarados libres de sospecha de minas en Colombia: El Dorado (Meta), Zambrano (Bolívar), Guatapé, La Unión, Nariño, San Carlos y San Francisco (Antioquia) y San Vicente de Chucurí (Santander) (Semana, 2016).

13 Los delitos de lesa humanidad son aquellos que se cometen reiteradamente y sistemáticamente contra la humanidad de una persona, de su familia o de la comunidad en la que vive. Los actos o acciones que se consideran dentro de delitos o crímenes de lesa humanidad, según los Estatutos de la Corte Penal Internacional, son asesinato: acabar con la vida de una persona, de su familia y de sus seres más cercanos. Exterminio: acabar de forma absoluta con todos los miembros de una comunidad. Esclavitud: forzar a ejercer trabajos sin remuneración a una persona o a varias. Deportación o traslado forzoso de población: desplazamiento forzado de una comunidad de sus lugares de origen. Encarcelamiento: privar de la libertad a una persona. Tortura: provocar dolor absoluto a una persona. Violación, esclavitud sexual, prostitución forzada, embarazo forzado, esterilización forzada u otros abusos sexuales de gravedad comparable: acabar con la integridad de una persona mediante un acto sexual. Persecución de un grupo o una colectividad: perseguir a un grupo de personas solo por diferencias ideológicas. Desaparición forzada de personas: secuestro reiterado y sistemático. Otros actos inhumanos: acciones que causen dolor físico o mental. 
- La tarea del desminado no se podrá culminar ni en el tiempo ni en las condiciones establecidas, dado que no solo las FARC han emplazado MAP y artefactos explosivos, sino que también la guerrilla del ELN, las bandas criminales emergentes BACRIM y los paramilitares siguen con estas prácticas, en algunas zonas del país, ${ }^{14}$ lo que dificulta aún más esta ardua labor. En este orden de ideas, hasta tanto no se llegue a un acuerdo negociado con estos grupos al margen de la ley, no se podrá hablar de un escenario de posconflicto ni de una paz estable y duradera; por el contrario, el país se expondría al recrudecimiento del conflicto en Colombia.

- Las minas y artefactos explosivos que han utilizado las FarC en el conflicto son únicos en su especie, de fabricación meramente artesanal y rustica. Esto quiere decir que para su improvisada elaboración se utilizan materiales diferentes del metal, como el vidrio, tubos de PVC, botellas de plástico, jeringas, entre otros, los cuales no pueden ser encontrados fácilmente por los detectores de metales. Esta situación obliga al Estado a replantear el actual Plan de Desminado y buscar nuevas estrategias, técnicas y en especial tecnológicas que permitan avanzar rápidamente en el desminado.

- Colombia tiene una accidentada topografía y desafortunadamente los territorios minados se encuentran en terrenos muy montañosos, en zonas selváticas y en paramos, lugares de muy difícil acceso donde solo se puede llegar caminando o a lomo de mula, hecho que dificulta el paso de personas y con ellas el de las herramientas tecnológicas, que en la mayoría de los casos son de gran tamaño y complejas de transportar. De allí la importancia que el país tecnifique mucho mejor este proceso e invierta recursos en todos los aspectos para la investigación, innovación y desarrollo de nuevas formas de desminado, con el fin de que este aspecto no se convierta en un obstáculo para el cumplimiento jurídico adquirido por Colombia internacionalmente.

\section{Acuerdo de paz y desminado humanitario}

Tras la finalización del conflicto armado interno de más larga duración en América Latina, el Gobierno nacional y las FARC han decidido de manera voluntaria dar por terminados 50 años de horror y sufrimiento, que solo han dejado víctimas, pobreza, incertidumbre, abandono y atraso en la población colombiana. Este acontecimiento, desde todo punto de vista histórico para el país, significa la reconstrucción de la democracia y del tejido humano, social, cultural, político y económico, en especial de 
aquellos que por la dinámica del conflicto han estado apartados del desarrollo y de oportunidades que garanticen el goce de una vida digna.

Dicha manifestación de la voluntad quedó plasmada el pasado 24 de noviembre de 2016, en el Acuerdo final para la terminación del conflicto y la construcción de una paz estable y duradera. Este último se compone de seis acuerdos que forman un todo y que pretenden garantizar la aplicabilidad de los derechos constitucionales, especialmente en la población víctima de la violencia.

El acuerdo final está constituido por los siguientes puntos (Oficina del Alto Comisionado para la Paz, 2017):

Punto 1: contiene el acuerdo "Reforma rural integral", que contribuirá a la transformación estructural del campo, y de esta manera se cierran las brechas entre el campo y la ciudad, y se crean condiciones de bienestar y buen vivir para la población rural. La reforma rural integral debe integrar las regiones, contribuir a erradicar la pobreza, promover la igualdad y asegurar el pleno disfrute de los derechos de la ciudadanía.

Punto 2: contiene el acuerdo "Participación política: apertura democrática para construir la paz". La construcción y consolidación de la paz, en el marco del fin del conflicto, requiere de una ampliación democrática que permita el surgimiento de nuevas fuerzas en el escenario político para enriquecer el debate y la deliberación alrededor de los grandes problemas nacionales y, de esa manera, fortalecer el pluralismo y, por tanto, la representación de las diferentes visiones e intereses de la sociedad, con las debidas garantías para la participación y la inclusión política.

La implementación del acuerdo final contribuirá a la ampliación y profundización de la democracia, por cuanto implicará la dejación de las armas y la proscripción de la violencia como método de acción política para todas y todos los colombianos, a fin de transitar a un escenario donde impere la democracia, con garantías plenas para quienes participen en política. Esto abrirá nuevos espacios para la participación

Punto 3: contiene el acuerdo "Cese al fuego y de hostilidades bilateral y definitivo y la dejación de las armas", que tiene como objetivo la terminación definitiva de las acciones ofensivas entre la fuerza pública y las FARC, y en general de las hostilidades y cualquier acción prevista en las reglas que rigen el cese, incluyendo la afectación a la población, y de esa manera crear las condiciones para el inicio de la implementación del acuerdo final y la dejación de las armas, y preparar la institucionalidad y al país para la reincorporación de las FARC a la vida civil.

Contiene también el acuerdo "Reincorporación de las FARC-EP a la vida civil en lo económico, lo social y lo político de acuerdo con sus intereses”. Sentar las bases para la construcción de una paz estable y duradera requiere la reincorporación efectiva de las FARC a la vida social, económica y política del país; dicha reincorporación ratifica el compromiso de las FARC de cerrar el capítulo del conflicto interno, convertirse en 
actor válido dentro de la democracia y contribuir decididamente a la consolidación de la convivencia pacífica, a la no repetición y a transformar las condiciones que han facilitado la persistencia de la violencia en el territorio.

Punto 4: contiene el acuerdo "Solución al problema de las drogas ilícitas". Para construir la paz es necesario encontrar una solución definitiva al problema de las drogas ilícitas, incluyendo los cultivos de uso ilícito y la producción y comercialización de estas. Para esto se promueve una nueva visión que dé un tratamiento distinto y diferenciado al fenómeno del consumo, al problema de los cultivos de uso ilícito y a la criminalidad organizada asociada al narcotráfico, asegurando un enfoque general de derechos humanos y salud pública, diferenciado y de género. Este punto enuncia vagamente el tema del desminado.

Punto 5: contiene el acuerdo "Víctimas". Desde el encuentro exploratorio de 2012, acordamos que el resarcimiento de las víctimas debería estar en el centro de cualquier acuerdo. El acuerdo crea el Sistema Integral de Verdad, Justicia, Reparación y no Repetición, que contribuye a la lucha contra la impunidad combinando mecanismos judiciales que permiten la investigación y sanción de las graves violaciones a los derechos humanos y las graves infracciones al derecho internacional humanitario, con mecanismos extrajudiciales complementarios que contribuyan al esclarecimiento de la verdad de lo ocurrido, la búsqueda de los seres queridos desaparecidos y la reparación del daño causado a personas, a colectivos y a territorios enteros.

El Sistema Integral de Verdad, Justicia, Reparación y no Repetición está compuesto por la Comisión para el Esclarecimiento de la Verdad, la Convivencia y la No Repetición, la Unidad Especial para la Búsqueda de Personas dadas por desaparecidas en el contexto y en razón del conflicto armado; la Jurisdicción Especial para la Paz; las Medidasde reparación integral para la construcción de la paz, y las Garantías de No Repetición.

Punto 6: contiene el acuerdo "Mecanismos de implementación y verificación", en el que se crea una Comisión de Seguimiento, Impulso y Verificación a la Implementación del Acuerdo Final, integrada por representantes del Gobierno nacional y de las Farc. Tiene como fin, entre otros, hacer seguimiento a los componentes del acuerdoy verificar su cumplimiento, servir de instancia para la resolución de diferencias, y el impulso y seguimiento a la implementación legislativa.

Los seis puntos anteriores son en teoría una oportunidad de paz, el resultado de la participación y el diálogo entre los diferentes actores y sectores de la sociedad, el sentir nacional plasmado en lo intangible, pues tan solo su rápida y efectiva implementación constituirá la transformación tangible del país. Sin embargo, y después de analizar cada uno de los puntos del acuerdo de paz, se puede deducir que el tema del desminado no es abarcado en las dimensiones que se requieren, ni se le da la importancia que realmente tiene, toda vez que es un aspecto tan relevante para la 
consecución de la paz, que condiciona la solución de otras problemáticas también inmersas en el acuerdo, como la restitución de tierras, el desarrollo rural, el acceso a la propiedad y el restablecimiento de los derechos fundamentales de las víctimas.

El acuerdo final contiene 310 páginas excedidas de "buenas intenciones"; por un lado, de las FARC, pues se comprometen a desarmarse, reincorporarse a la vida civil y dar por terminados 50 años de conflicto y lucha política; por otro lado, del Gobierno, que a cambio garantiza la seguridad de los guerrilleros que se reintegren a la vida social y política. Pero en este código de buenas prácticas, lamentablemente solo se habla de desminado humanitario en cinco de ellas, no existe un párrafo o tan siquiera un punto que plante específicamente la estrategia que tiene el Gobierno en el mediano plazo para solucionar a cabalidad este tema, no se trata únicamente de encontrar y destruir las minas y con ello aumentar día a día positivamente las estadísticas, sino de garantizar el derecho al uso de la tierra, al libre tránsito de todas las personas por todos aquellos municipios que hoy se encuentran contaminados. No puede quedar hecha la tarea a medias, no se puede fallar en este intento, sería el caldo de cultivo perfecto para los detractores de la paz.

Los numerales 3, 4 y 5 del acuerdo de paz se refieren en algunos de sus apartes al tema del desminado y la descontaminación de territorios por MAP. A continuación, se presentan algunos de sus enunciados. ${ }^{15}$

\section{Numeral 3. "Cese al fuego y de hostilidades bilateral y definitivo y la dejación de las armas"}

\subsubsection{Procedimiento}

Con la firma del acuerdo final inicia el proceso de dejación de las armas de las FARC, de la siguiente manera.

Para la planeación y el alistamiento de la logística para dejación de armas (DA), las FARC, a partir del día D+5 suministra al Componente Internacional de Mecanismos de Monitoreo y Verificación (CI-MM\&v) la información que el CI-MM\&v considere necesaria, para el transporte, registro, identificación, monitoreo y verificación de la tenencia, recolección, almacenamiento, extracción y disposición final.

Las FARC contribuyen por diferentes medios, incluyendo el suministro de información, con la limpieza y descontaminación de los territorios afectados por MAP, artefactos explosivos improvisados (AEI) y MUSE o restos explosivos de guerra (REG) en general, teniendo en cuenta lo acordado en los puntos 4 y 5 , y lo que se acuerde en

15 Véase: http://www.altocomisionadoparalapaz.gov.co/herramientas/Documents/Lo-que-hemos-acordadoel-acuerdo-final-de-paz.pdf 
el punto de reincorporación a la vida civil en cuanto a la participación de las FARC en la acción contra minas.

\section{Numeral 4. "Solución al problema de las drogas ilícitas"}

\subsubsection{Condiciones de seguridad para las comunidades y los territorios afectados por los cultivos de uso ilícito}

En adición a la generación de condiciones para la satisfacción de los derechos económicos y sociales de la población y para el desarrollo integral, la sostenibilidad del Programa Nacional Integral de Sustitución de Cultivos de Uso Ilícito (PNIS) y el cumplimiento de sus objetivos requieren, al mismo tiempo, la provisión de garantías y condiciones de seguridad para las comunidades y los territorios afectados por los cultivos de uso ilícito, mediante el fortalecimiento de la presencia institucional del Estado y de sus capacidades de protección de las comunidades, en especial frente a cualquier tipo de coacción o amenaza, y de sus capacidades de interdicción y judicialización de las redes territoriales de narcotráfico, según la concepción de seguridad contemplada en el acuerdo final.

La protección de las comunidades, la garantía del derecho a la vida y el bienestar de la población rural necesita también asegurar el desminado, para lo cual el Gobierno nacional, tras la firma del acuerdo final y en el marco de su implementación, pondrá en marcha un programa de desminado y limpieza de las áreas del territorio nacional que hubiesen sido afectadas por la ubicación de minas antipersonal y municiones sin explotar. Este es un propósito mancomunado al que contribuirán el Gobierno y las FARC por diferentes medios y en lo que le corresponda a cada cual, incluyendo el suministro de información, en los términos que se consignen en el acuerdo final y como parte del compromiso mutuo con el fin del conflicto y la construcción de una paz estable y duradera.

\section{Numeral 5. "Reparación de víctimas: Sistema Integral de Verdad, Justicia, Reparación y No Repetición”, incluyendo la Jurisdicción Especial para la Paz, y el compromiso sobre derechos humanos}

\subsubsection{Acciones concretas de contribución a la reparación}

Las FARC se comprometen en el proceso de reincorporación a la vida civil y, como parte de dicho proceso, a realizar acciones de contribución a la reparación por los daños causados que podrán incluir, entre otras, la participación en obras de reconstrucción de infraestructura en los territorios más afectados por el conflicto; la participación 
en los programas de limpieza y descontaminación de los territorios de MAP, AEI y MUSE O REG; la participación en los programas de sustitución de cultivos de uso ilícito; la contribución a la búsqueda, ubicación, identificación y recuperación de restos de personas muertas o dadas por desaparecidas en el contexto y con ocasión del conflicto, y la participación en programas de reparación del daño ambiental, como por ejemplo la reforestación.

\section{Conclusión}

El concepto de desminado puede considerarse subjetivo en el contexto del conflicto armado colombiano, dado que las estadísticas realizadas para determinar el impacto que tiene este flagelo en el país no son del todo precisas, pues la mayoría de los guerrilleros explosivistas de las FARC que intervinieron directamente en el emplazamiento de estos artefactos murieron en combate, están desaparecidos o simplemente desconocen con exactitud dónde fueron puestas, de allí la imposibilidad del Estado de garantizar el desminado total en los territorios afectados.

El incumplimiento de lo pactado en el acuerdo de paz a mediano plazo generara desconfianza e incertidumbre en la sociedad civil que verá cómo sus derechos fundamentales nuevamente son vulnerados, al no poder retornar a sus lugares de origen, lo que perpetúa su condición de víctimas de la violencia; además, en la comunidad internacional, que tiene puestos los ojos en este tema. De allí que su ejecución al $100 \%$ debe ser fundamental para la consecución de una verdadera paz estable y duradera.

$\mathrm{Al}$ inicio del proceso de negociación entre el Gobierno colombiano y las FARC (principal actor del conflicto armado, así como el victimario que más artefactos explosivos ha emplazado en el país), pocos entendieron el impacto que tendría para la construcción de la paz la implementación de un ambicioso plan estratégico contra las MAP, pues se ponía sobre la mesa por primera vez en 27 años esta problemática que ha dejado más de 11.000 víctimas desde 1990 y, lo que es más loable aún, conseguir que este grupo armado renunciara por siempre a seguir cometiendo esta práctica inhumana. Esta decisión se logró gracias a la voluntad desinteresada de las partes de firmar un acuerdo de paz, pero además existen de por medio intereses políticos y económicos muy importantes para las dos partes, que terminan cediéndose en nombre de la paz. Los mecanismos de disuasión y conveniencia manejados entre las partes en el proceso de negociación sustentan la idea de que "el fin justifica los medios", pues la paz estable y duradera, a todas luces, tiene un precio.

El objetivo de que Colombia sea un país libre de minas antipersonales en 2021 depende en gran medida de la veracidad en las estadísticas existentes sobre desminado 
humanitario y artefactos explosivos a nivel nacional, pues con dicha información se podrá trazar la hoja de ruta que conduzca a determinar si existen actividades, eventos o víctimas sin registrar, y con ello proceder a levantar las alertas y soluciones respectivas.

A la fecha no existe en Colombia una información confiable sobre el número de minas emplazadas realmente ni su ubicación a pesar de las diversas fuentes de información gubernamentales y no gubernamentales que existen sobre el tema. Esta situación imposibilitará el cumplimiento internacional que tiene el país, así como la entrega parcial de algunos territorios desminados a la población civil dentro del plazo acordado. Vale la pena recordar que en Nicaragua el proceso de desminado duró más de dos décadas. Teniendo en cuenta esto, si en Colombia no se cumple el acuerdo, la ayuda financiera internacional quedaría en riesgo y condicionada a la nueva e impredecible política exterior de la Casa Blanca y los otros países cooperantes.

Si el acuerdo de paz no se blinda lo suficiente y se soporta en una política pública fuerte respaldada por el Estado, y dadas las nuevas tendencias políticas presentes en algunos países como Estados Unidos y el Reino Unido, podría surgir y ser elegido un líder populista que derogue lo ya pactado, y se pondría en riesgo la culminación del plan estratégico de desminado y, en consecuencia, el propio acuerdo de paz.

Es importante que el Gobierno nacional avance rápidamente en los diálogos de paz con el ELN, y otros grupos al margen de la ley como las BACRIM y los grupos paramilitares, si se quiere garantizar la sostenibilidad tanto del acuerdo de paz en general, como del proceso de desminado en particular, y asegurar que en el futuro no vuelva a ser minado el territorio colombiano.

La Campaña Internacional para la Prohibición de las Minas Antipersonales (ICBL, por sus siglas en inglés) publicó hace cinco meses el Landmine Monitor, ${ }^{16}$ que año tras año actualiza la posición en la que se encuentran a nivel mundial los países más afectados por minas y artefactos explosivos, que Colombia pasó de ocupar el deshonroso segundo puesto de los países con más víctimas, después de Afganistán, al sexto lugar. Este resultado, poco alentador aún, obedece sin lugar a dudas a la ardua tarea que el Estado y las organizaciones internacionales han venido adelantando con el tema del desminado. Sin embargo, no nos podemos conformar con ocupar un sexto lugar en dicho ranking; el objetivo trazado supone no estar en ninguno de estos listados en 2021.

16 The Landmine Monitor cubre la política de prohibición de minas, el uso, la producción, el comercio y el almacenamiento en todos los países del mundo, e incluye información sobre contaminación, eliminación, víctimas, asistencia a las víctimas y apoyo a la acción contra las minas. El informe se centra en 2015, con la información incluida hasta noviembre de 2016. 
El Gobierno Colombiano debería incentivar una política pública de innovación tecnológica para el tema del desminado, teniendo en cuenta la particularidad, el riesgo y la complejidad que tiene este proceso en cuanto a la excavación y destrucción de las minas antipersonales, con el fin de garantizar la reducción de los tiempos empleados para su desactivación y la vida de las personas que ejecutan esta heroica labor.

\section{Referencias}

Comité Internacional de la Cruz Roja (CICR). (2012). Minas antipersonal. Recuperado de https://www.icrc.org/spa/war-and-law/weapons/anti-personnel-landmines/overview-anti-personnel-landmines.htm

Dirección para la Acción Integral contra Minas Antipersonal (DAICMA). (2014). Depuración registros duplicados base de datos de víctimas de la dirección para la acción integral contra minas antipersonal. Bogotá: Presidencia de la República.

Dirección para la Acción Integral Contra Minas Antipersonal (DAICMA). (2016). Listado de departamentos asignados, pendientes por asignar y asignados para estudios no técnicos para ser intervenidos con actividades de desminado humanitario. Bogotá: Presidencia de la República.

Dirección para la Acción Integral Contra Minas Antipersonal (DAICMA). (2017). Víctimas de minas antipersonal. Bogotá: Presidencia de la República.

El Tiempo (s. f.). La Colombia que se va a desminar y la que seguirá en riesgo. Recuperado de http://www.eltiempo.com/multimedia/especiales/situacion-de-minas-antipersona-en-colombia/15714557/1/index.html

Noguera, S. (19 de agosto de 2016). Los conflictos a enfrentar después del proceso de paz. El Espectador Recuperado de http://colombia2020.elespectador.com/ pais/los-conflictos-enfrentar-despues-del-proceso-de-paz

Oficina del Alto Comisionado para la Paz. (2017). Acuerdo final para la terminación del conflicto y la construcción de una paz estable $y$ duradera. Bogotá: Presidencia de la República.

Organización de las Naciones Unidas (ONU). (1997). Convención sobre la prohibición del empleo, almacenamiento, producción y transferencia de minas antipersonal y sobre su destrucción. Tratado de Ottawa. Nueva York: autor. 
Programa Presidencial para la Acción Integral Contra Minas Antipersonal (PAICMA). (2017). Informe del programa presidencial para la acción integral contra minas antipersonal. Bogotá: Presidencia de la República.

RCN Radio. (2 de marzo de 2016). Alerta en san carlos, antioquia, por el hallazgo de tres minas antipersona. RCN Radio. Recuperado de http://www.rcnradio.com/locales/alerta-san-carlos-antioquia-hallazgo-tres-minas-antipersona/

Roa, D. (2000). Colombia y las minas antipersonal: Sembrando minas, cosechando muerte. Bogotá: Unicef.

Semana. (2016). Minas, el enemigo oculto. Recuperado de http://minas.semana.com/ salida.php

Unicef. (2000). Colombia y las minas antipersonal: Sembrando minas, cosechando muerte. Bogotá: Crear y Comunicar. 
Esta obra se editó en Ediciones USTA, Departamento

Editorial de la Universidad Santo Tomás. Se usó papel esmaltado de 300 gramos para la carátula y papel bond beige de 70 gramos para páginas internas.

Tipografía: Minion Pro. y Myriad Pro

Impreso por Xpress Estudio Gráfico y Digital S. A. S. 2018. 
El siglo XXI es una sucesión de transformaciones políticas, sociales, económicas y culturales, a las que los ciudadanos se encuentran enfrentados constantemente. Esto implica que la ciencia política, las relaciones internacionales y las ciencias afines no pueden quedarse atrás en la comprensión de estas dimensiones globales que conllevan estos cambios estatales. Por esta razón, el libro Gobernanza multidimensional se adentra en el nuevo universo teórico de lo que significan estos dos conceptos, así como sus implicaciones en las prácticas y procesos de gobierno de las sociedades hoy en día.

Este texto recopila las reflexiones de varios autores acerca de lo que significa gobernar en nuestro siglo y propone maneras de abordar la gobernanza poniéndola en diversos contextos tales como el gobierno local, las políticas públicas, la ciudadanía igualitaria, la territorialidad, la e-gobernabilidad, la seguridad, el gobierno marítimo, el posconflicto y el desminado en Colombia.

De esta forma, presentamos una mirada a la Gobernanza multidimensional donde hacemos una invitación al lector a ahondar en el estudio del tema que está transformando la manera en que se ve y se entiende los asuntos públicos en nuestros tiempos.

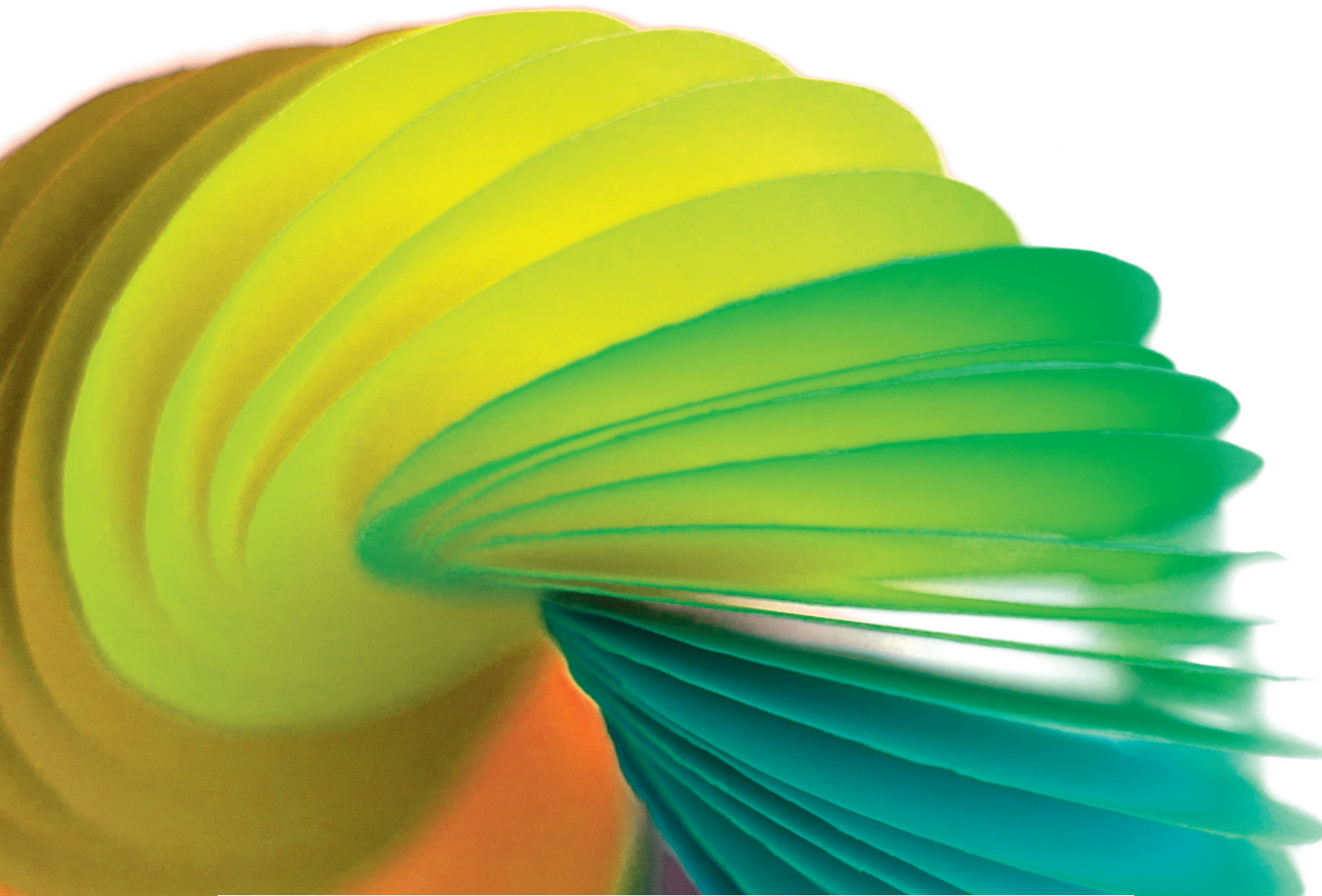

